\title{
In vitro susceptibility to pyrimethamine of DHFR I164L single mutant Plasmodium falciparum
}

\author{
Valérie Andriantsoanirina ${ }^{1,2^{*}}$, Rémy Durand ${ }^{2}$, Bruno Pradines ${ }^{3}$, Eric Baret ${ }^{3}$, Christiane Bouchier ${ }^{4}$, \\ Arsène Ratsimbasoa ${ }^{5}$ and Didier Ménard ${ }^{1,6}$
}

\begin{abstract}
Background: Recently, Plasmodium falciparum parasites bearing Pfdhfr 1164L single mutation were found in Madagascar. These new mutants may challenge the use of antifolates for the intermittent preventive treatment of malaria during pregnancy (IPTp). Assays with transgenic bacteria suggested that 1164L parasites have a wild-type phenotype for pyrimethamine but it had to be confirmed by testing the parasites themselves.

Methods: Thirty Plasmodium falciparum clinical isolates were collected in 2008 in the south-east of Madagascar. A part of Pfdhfr gene encompassing codons 6 to 206 was amplified by PCR and the determination of the presence of single nucleotide polymorphisms was performed by DNA sequencing. The multiplicity of infection was estimated by using an allelic family-specific nested PCR. Isolates that appeared monoclonal were submitted to culture adaptation. Determination of $I_{50 \text { s }}$ to pyrimethamine was performed on adapted isolates.

Results: Four different Pfdhfr alleles were found: the $164 \mathrm{~L}$ single mutant-type $(\mathrm{N}=13)$, the wild-type $(\mathrm{N}=7)$, the triple mutant-type $511 / 59 \mathrm{R} / 108 \mathrm{~N}(\mathrm{~N}=9)$ and the double mutant-type 108N/164L ( $\mathrm{N}=1)$. Eleven out $30(36.7 \%)$ of $P$. falciparum isolates were considered as monoclonal infection. Among them, five isolates were successfully adapted in culture and tested for pyrimethamine in vitro susceptibility. The wild-type allele was the most susceptible with a $50 \%$ inhibitory concentration $\left(I C_{50}\right)<10 \mathrm{nM}$. The geometric mean of $I_{50}$ of the three $\mid 164 \mathrm{~L}$ mutant isolates was 6-fold higher than the wild-type with $61.3 \mathrm{nM}(\mathrm{SD}=3.2 \mathrm{nM}, \mathrm{Cl} 95 \%$ : 53.9-69.7 nM). These values remained largely below the $\mathrm{IC}_{50}$ of the triple mutant parasite $(13,804 \mathrm{nM})$.

Conclusion: The $\mathrm{I}_{50} \mathrm{~S}$ of the $1164 \mathrm{~L}$ mutant isolates were significantly higher than those of the wild-type (6-fold higher) and close from those usually reported for simple mutants S108N (roughly10-fold higher than wild type). Given the observed values, the determination of $\mathrm{IC}_{50} \mathrm{~S}$ directly on parasites did not confirm what has been found on transgenic bacteria. The prevalence increase of the Pfdhfr $1164 \mathrm{~L}$ single mutant parasite since 2006 could be explained by the selective advantage of this allele under sulphadoxine-pyrimethamine pressure. The emergence of highly resistant alleles should be considered in the future, in particular because an unexpected double mutant-type allele S108N/1164L has been already detected.
\end{abstract}

\section{Background}

Plasmodium falciparum malaria remains a major cause of morbidity and mortality in endemic areas, affecting mainly African children under five years of age and pregnant women [1]. Currently, in these areas, artemisinin combinations therapy (ACT) is recommended as first-line treatment for uncomplicated P. falciparum malaria, while the intermittent preventive treatment of

\footnotetext{
* Correspondence: landyvalerie@gmail.com

'Unité de Recherche sur le Paludisme, Institut Pasteur, Antananarivo, Madagascar

Full list of author information is available at the end of the article
}

malaria in pregnancy (IPTp) relies on the administration of antifolate sulphadoxine-pyrimethamine (SP) combination. Anti-malarial drugs used for IPTp must be efficacious, safe, tolerable, cheap, and easy to administer, preferably as a single dose [2]. So far, SP is the only drug which has these attributes, despite its decreasing efficiency [3].

Analysis of the molecular basis of anti-malarial drug resistance has demonstrated that mutations in the dihydrofolate reductase $(d h f r)$ and dihydropteroate synthase genes are associated with development of SP resistance. Resistance to pyrimethamine (PYR) is due to point

\section{(Ciomed Central}


mutations in the P. falciparum dihydrofolate reductase gene (Pfdhfr) [4-9] and the PfDHFR S108N point mutation is the main molecular event, followed by stepwise selection of additional mutations in other positions (codons 51, 59 and 164). Several studies have already demonstrated that parasites with a triple-mutant allele (N51I/C59R/S108N) have markedly reduced in vitro susceptibility to PYR, and the presence of the triple-mutation allele increases the risk of SP therapeutic failure [10]. An additional mutation, I164L, confers to the quadruple mutant a high level of resistance to PYR [11], abrogating the clinical efficacy of SP as observed in Southeast Asia and South America [12] but rarely in Africa [13].

In African countries and the Comoros Island, three haplotypes including the $1164 \mathrm{~L}$ allele have been described: both triple mutants N51I/S108N/I164L and C59R/S108N/I164L, and the quadruple mutant $[14,15]$. In 2006, a novel I164L single mutant in one field isolate in Madagascar was observed [16]. In 2008, the Pfdhfr I164L polymorphism was prevalent in southern sentinel sites of the Great Island with $8.8 \%$ of isolates carrying this mutation [14]. Microsatellite markers analysis showed that this unique allele emerged independently in these sites. Until now, the Pfdhfr I164L allele has not been reported elsewhere in the world. Previous published data have also shown that the triple mutant N51I/C59R/S108N have largely spread in Madagascar but the quadruple mutant has not been reported so far.

In 2009, Lozovsky et al have explored and analysed the possible evolutionary pathways of PYR resistance using experimental systems with transgenic bacteria in which all possible mutational intermediates were created by site-directed mutagenesis (N51I, C59R, S108N, and I164L) in PfDHFR enzyme [17]. Their findings suggested that $P$. falciparum parasites harbouring single mutant Pfdhfr I164L $\left(\mathrm{IC}_{50}=0.29 \mu \mathrm{g} / \mathrm{ml}\right)$ were as sensitive to PYR as the wild type allele $(0.27 \mu \mathrm{g} / \mathrm{ml})$. This data was not consistent with the observation of the rapid rise in the prevalence of parasites with the single $164 \mathrm{~L}$ mutation in Madagascar following the massive use of the SP [14].

In this context, the main objective of the study was to assess the PYR in vitro susceptibility of parasites themselves and to compare those harboring the single $164 \mathrm{~L}$ mutation with those harbouring wild-type and triplemutant Pfdhfr alleles in order to decipher the epidemiological characteristics of this haplotype.

\section{Methods}

\section{Sample collection}

Plasmodium falciparum clinical isolates were collected in 2008 from patients seeking treatment for malaria at Farafangana Health Centre in the south-east of
Madagascar where high prevalence of Pfdhfr I164L single mutant allele was previously observed [18]. All patients with fever were screened with the CareStart ${ }^{\circ}$ rapid diagnostic test $\left(\right.$ AccessBio $\left.^{\circ}\right)$. Giemsa-stained thin and thick blood films were prepared for each patient with a positive rapid diagnostic test result. The various species of Plasmodium were identified and parasitaemia was assessed by a skilled microscopist. Once informed consent had been obtained from all adults and from at least one parent for minors, $5 \mathrm{ml}$ of venous blood were collected on EDTA tube. Patients with positive microscopy results were promptly treated according to National Malaria Policy. Blood samples were sent to Institut Pasteur, Antananarivo, at $+4^{\circ} \mathrm{C}$ within 24 to 48 $\mathrm{h}$ of collection. Giemsa-stained thin blood smears were examined to check for mono-infection with $P$. falciparum and to determine parasite density. Plasmodium falciparum samples were split into two different aliquots: cryopreserved aliquots stored in liquid nitrogen for culture adaptation and in vitro assays, and fresh blood aliquots stored at $-20^{\circ} \mathrm{C}$ until genomic DNA extraction.

\section{Genomic DNA extraction}

DNA was extracted from initial infected blood aliquots and from parasites obtained after culture adaptation, by the phenol-chloroform method [19].

\section{Plasmodium species molecular diagnosis}

Parasite species were confirmed in both DNA extracts by real-time PCR, using species-specific primers as described by de Monbrison [20] with a protocol adapted for the RotorGene ${ }^{\circledR} 3000$ thermocycler (Corbett Life Science ${ }^{\circledR}$, Sydney, Australia).

\section{Pfdhfr amplification \& sequencing}

A 600 bp fragment of Pfdhfr gene encompassing codons 6 to 206 was amplified by nested PCR technique on both DNA extracts, as previously described [21]. Sequencing reactions were carried out with a ABI Prism BigDye Terminator cycle sequencing ready reaction kit and were run on a model $3730 \mathrm{xl}$ genetic analyzer (Applied Biosystems, Courtaboeuf, France). Electrophoregrams were visualized and analyzed with CEQ2000 genetic analysis system software (Beckman Coulter, Villepinte, France). The amino acid sequences were compared with the 3D7 PfDHFR wild-type amino acid sequence (PFD0830w, GenBank accession number AL844503). The presence of single nucleotide polymorphisms was confirmed by reading both the forward and the reverse strands. Parasites with mixed alleles (in which both wild-type and mutant alleles were present) were considered mutants. Haplotypes for drug resistance markers were reconstructed from the full sequence 
presenting an unambiguous single allele signal at all positions.

\section{Multiplicity of infection (MOI)}

The multiplicity of infection, defined as the highest number of alleles detected at either of the two loci, was estimated by using an allelic family-specific nested PCR (MAD20, K1, and RO33 for Pfmsp-1 and 3D7 and FC27 for Pfmsp-2), as described previously (1). All PCR amplifications of initial infected blood aliquots contained a positive control (genomic DNA from strains W2, HB3, and 3D7) and a negative control (no target DNA). Only samples showing monoclonal P. falciparum infections were selected for culture adaptation.

\section{Culture adaptation and in vitro susceptibility assays}

Aliquots preserved in liquid nitrogen were sent to IRBA, Marseille, France, for culture adaptation and assessment of $50 \%$ inhibitory concentration $\left(\mathrm{IC}_{50}\right)$ to PYR. PYR was obtained from Sigma (St. Louis, MO). Stock solution was prepared in ethanol. Twofold serial dilutions were prepared in sterile water and distributed in triplicate into Falcon 96-well flat-bottomed plates (Becton Dickinson, Franklin Lakes, NJ). The 3D7 clone (wild-type Pfdhfr allele) and the W2 Indochina clone (triple mutant-type Pfdhfr allele) were obtained from MR4ATCC (Manassas, VA, USA) and used as controls to test the batch of plates.

Determination of the in vitro susceptibility was performed in triplicate on culture adapted isolates and on references strains, using the in vitro isotopic microtest as previously described [22]. The $50 \%$ inhibitory concentration $\left(\mathrm{IC}_{50}\right)$, i.e., the drug concentration corresponding to $50 \%$ of the uptake of $\left[{ }^{3} \mathrm{H}\right]$ hypoxanthine by the parasites in drug-free control wells, was determined by nonlinear regression analysis of log dose-response curves (Riasmart; Packard, Meriden, NJ). Data were analysed after logarithmic transformation and expressed as the geometric mean $\mathrm{IC}_{50}$, and $95 \%$ confidence intervals were calculated (Stata 9; StataCorp LP, Texas, USA).

\section{Ethical approval}

The study protocol was reviewed and approved by the Ethics Committee of the Ministry of Health of Madagascar $\left(\mathrm{N}^{\circ} 007 / \mathrm{SANPF} / 2007\right)$. An informed written consent was provided by the parents/guardians of all patients before they were included in the study.

\section{Results}

Thirty $P$. falciparum samples were collected in a fourday mission with parasitaemia ranging from 0.01 to $0.72 \%$. Among them, sequencing of the Pfdhfr gene revealed four different alleles: the 164L single mutanttype $(\mathrm{N}=13)$, the wild-type $(\mathrm{N}=7)$, the triple mutant- type $51 \mathrm{I} / 59 \mathrm{R} / 108 \mathrm{~N}(\mathrm{~N}=9)$ and the double mutant-type $108 \mathrm{~N} / 164 \mathrm{~L}(\mathrm{~N}=1)$. The latter allele was observed for the first time in this area.

Genotyping of collected isolates showed that 11/30 (36.7\%) of P. falciparum isolates had a single allelic form and were considered as monoclonal infection: 164L single mutant-type allele (4/13), wild-type allele (2/ $7)$, triple mutant-type 51I/59R/108N allele (4/9) and double mutant-type allele 108N/164L (1/1). Among them, five isolates were successfully adapted in culture (1 isolate with wild-type allele, three isolates with $164 \mathrm{~L}$ single mutant-type allele and one isolate with triple mutant-type 51I/59R/108N allele) and tested for PYR in vitro susceptibility. On these samples, Pfdhfr genotypes and MOI which were assessed after the culture adaptation period were identical to initial samples.

Pyrimethamine $\mathrm{IC}_{50} \mathrm{~s}$ were significantly different among the three Pfdhfr alleles $(\mathrm{P}<0.001)$. The wildtype allele was the most susceptible with an $\mathrm{IC}_{50}<10$ $\mathrm{nM}$. The geometric mean of $\mathrm{IC}_{50}$ of the three $\mathrm{I} 164 \mathrm{~L}$ mutant isolates was significantly higher $(6$-fold, $\mathrm{P}<$ $0.001)$ than the wild-type with $61.3 \mathrm{nM}(\mathrm{SD}=3.2 \mathrm{nM}$, CI95\%: 53.9-69.7 nM). These values remained largely below the $\mathrm{IC}_{50}$ of the triple mutant parasite tested in the assay which was $13,804 \mathrm{nM}$.

\section{Discussion \& Conclusion}

The main result of this study was that $1164 \mathrm{~L}$ mutant isolates did not show fully susceptible $\mathrm{IC}_{50} \mathrm{~s}$, but values that were significantly higher than those of the wildtype (six-fold higher). These values were nearer to what is usually reported for simple mutants S108N (roughly10-fold higher than wild type) [23]. Thus, the determination of $\mathrm{IC}_{50}$ s directly on parasites did not confirm on that specific point what has been found by Lozowski et al using transgenic bacteria. The adaptation of isolates to culture conditions is a delicate process, which is not always successful. In the present study, three clonal infections by parasites harbouring the I164L mutations were adapted, which enabled us to observe the low SD of the $\mathrm{IC}_{50}$ s to PYR between these strains. Given the observed values of $\mathrm{IC}_{50} \mathrm{~s}$, the presence of Pfdhfr I164L single mutant parasites did not challenge the current use of SP for IPTp in Madagascar. Indeed, I164L mutant isolates could not been considered as resistant because the usual threshold for PYR resistance was defined as $>2,000 \mathrm{nM}$, the intermediate values, 100-2000 nM, representing moderate resistance [24]. However, the emergence of highly resistant alleles should be considered as possible for two reasons: first, the prevalence of the $1164 \mathrm{~L}$ allele has increased since year 2006 (14 isolates out 30 (46.7\%) in the present series) and second, the presence of the double mutant-type allele S108N/I164L has been detected in a monoclonal 
isolate. The latter means that the $108 \mathrm{~N} / 164 \mathrm{~L}$ genotype has been formed either on a background of S108N or I164L. This pathway was not expected according to the model of Lozovsky et al, but obviously it occurred in the real life. As I164L simple mutant genotype is not found today in another area in the world, Malagasy parasites may have a particular background, which enabled the emergence of this double mutant genotype. A highly resistant $\mathrm{IC}_{50}(103 \mu \mathrm{g} / \mathrm{ml})$ for the S108N/I164L genotype was found using transgenic bacteria [17]. Unfortunately, the S108N/I164L isolate was not successfully adapted to culture and it was consequently impossible to confirm this in vitro resistance level. Interestingly, these authors reported that the low fitness of the quadruple mutant in the absence of PYR was not observed in transgenic bacteria having the S108N/I164L genotype. If these characteristics were to apply to natural parasites, it could have implications in terms of transmission of these strains. The triple mutant-type $51 \mathrm{I} / 59 \mathrm{R} / 108 \mathrm{~N}$ was also largely prevalent (9 out $30(30 \%)$ isolates) in the area and may represent a possible background for the emergence of the quadruple mutant. In addition, the diffusion of the quadruple mutant from the Comoros Islands remains possible and could be a source of highly resistant parasites. Combinations of DHFR and DHPS inhibitors act synergistically. To further document the impact of the Pfdhfr I164L mutation in SP resistance it may be interesting to determine polymorphisms in Pfdhps gene, which was not done for isolates of the present series. A previous work performed in a large series in 2007 in Madagascar showed that 46\% of isolates harboured the Pfdhps A437G mutation [14]. For all these reasons, epidemiological surveillance is needed in the future to monitor the use of SP in IPTp.

\section{Acknowledgements}

We thank the patients and healthcare workers involved in the national network for the surveillance of malaria resistance in Madagascar (Réseau d'Etude de la Résistance, RER) from which these samples were obtained, and the staff of the Ministry of Health of Madagascar for their collaboration. This study was supported by grants from the Institut de Médecine et d'Epidémiologie Appliquée (IMEA), Fondation Léon M'Ba, Paris, France; Université Paris 13, Département Relation Européenne et Internationale, Bobigny, France and the Genomics Platform, Institut Pasteur, Paris, France. Samples collection in Madagascar was funded by the Global Fund to Fight AIDS, Tuberculosis and Malaria, round 3 (Community Action to Roll Back Malaria, grant no. MDG-304-G05-M). D. Ménard was supported by the French Ministry of Foreign Affairs during this work.

\section{Author details}

'Unité de Recherche sur le Paludisme, Institut Pasteur, Antananarivo, Madagascar. ${ }^{2}$ Laboratoire de Parasitologie-Mycologie, Hôpital Avicenne, 125 Rue de Stalingrad 93000 Cedex 8, Bobigny France. ${ }^{3}$ Unité de Parasitologie UMR6236, Institut de Recherche Biomédicale des Armées, Marseille, France. ${ }^{4}$ Plateforme Génomique, Institut Pasteur, Paris, France. ${ }^{5}$ Ministère de la Santé, du Planning Familial et de la Protection Sociale, Antananarivo, Madagascar. ${ }^{6}$ Unité d'Epidémiologie Moléculaire, Institut Pasteur, Phnom Penh, Cambodge.

\section{Authors' contributions}

$\mathrm{VA}, \mathrm{RD}$ and $\mathrm{DM}$ developed the study protocol, oversaw the implementation of the field work and the PCR analysis, and assisted with the data analysis and drafting of the manuscript. AR contributed to the field work. EB performed culture adaptation and in vitro assays. VA undertook real time and nested PCR assays. CB carried out sequencing. BP helped to write the manuscript and gave constructive advice. All authors read and approved the final manuscript.

\section{Competing interests}

The authors declare that they have no competing interests.

Received: 18 May 2011 Accepted: 27 September 2011

Published: 27 September 2011

\section{References}

1. Hay SI, Guerra CA, Gething PW, Patil AP, Tatem AJ, Noor AM, Kabaria CW, Manh BH, Elyazar IR, Brooker S, Smith DL, Moyeed RA, Snow RW: A world malaria map: Plasmodium falciparum endemicity in 2007. PLoS Med 2009, 6:e1000048.

2. Newman RD, Parise ME, Slutsker L, Nahlen B, Steketee RW: Safety, efficacy and determinants of effectiveness of antimalarial drugs during pregnancy: implications for prevention programmes in Plasmodium falciparum-endemic sub-Saharan Africa. Trop Med Int Health 2003, 8:488-506.

3. Aponte JJ, Schellenberg D, Egan A, Breckenridge A, Carneiro I, Critchley J, Danquah I, Dodoo A, Kobbe R, Lell B, May J, Premji Z, Sanz S, Sevene E, Soulaymani-Becheikh R, Winstanley $P$, Adjei S, Anemana $S$,

Chandramohan D, Issifou S, Mockenhaupt F, Owusu-Agyei S, Greenwood B, Grobusch MP, Kremsner PG, Macete E, Mshinda H, Newman RD, Slutsker L, Tanner M, Alonso P, Menendez C: Efficacy and safety of intermittent preventive treatment with sulfadoxine-pyrimethamine for malaria in African infants: a pooled analysis of six randomised, placebo-controlled trials. Lancet 2009, 374:1533-1542.

4. Basco LK, Eldin de Pecoulas P, Wilson CM, Le Bras J, Mazabraud A: Point mutations in the dihydrofolate reductase-thymidylate synthase gene and pyrimethamine and cycloguanil resistance in Plasmodium falciparum. Mol Biochem Parasitol 1995, 69:135-138.

5. Cowman AF, Morry MJ, Biggs BA, Cross GA, Foote SJ: Amino acid changes linked to pyrimethamine resistance in the dihydrofolate reductasethymidylate synthase gene of Plasmodium falciparum. Proc Natl Acad Sci USA 1988, 85:9109-9113.

6. Nzila-Mounda A, Mberu EK, Sibley CH, Plowe CV, Winstanley PA, Watkins WM: Kenyan Plasmodium falciparum field isolates: correlation between pyrimethamine and chlorcycloguanil activity in vitro and point mutations in the dihydrofolate reductase domain. Antimicrob Agents Chemother 1998, 42:164-169.

7. Peterson DS, Walliker D, Wellems TE: Evidence that a point mutation in dihydrofolate reductase-thymidylate synthase confers resistance to pyrimethamine in falciparum malaria. Proc Natl Acad Sci USA 1988, 85:9114-9118.

8. Plowe CV: The evolution of drug-resistant malaria. Trans $R$ Soc Trop Med Hyg 2009, 103(Suppl 1):S11-14

9. Snewin VA, England SM, Sims PF, Hyde JE: Characterisation of the dihydrofolate reductase-thymidylate synthetase gene from human malaria parasites highly resistant to pyrimethamine. Gene 1989, 76:41-52.

10. Gregson A, Plowe CV: Mechanisms of resistance of malaria parasites to antifolates. Pharmacol Rev 2005, 57:117-145.

11. Kiara SM, Okombo J, Masseno V, Mwai L, Ochola I, Borrmann S, Nzila A: In vitro activity of antifolate and polymorphism in dihydrofolate reductase of Plasmodium falciparum isolates from the Kenyan coast: emergence of parasites with Ile-164-Leu mutation. Antimicrob Agents Chemother 2009, 53:3793-3798.

12. Plowe CV, Kublin JG, Doumbo OK: P. falciparum dihydrofolate reductase and dihydropteroate synthase mutations: epidemiology and role in clinical resistance to antifolates. Drug Resist Updat 1998, 1:389-396.

13. Lynch C, Pearce R, Pota H, Cox J, Abeku TA, Rwakimari J, Naidoo I, Tibenderana J, Roper C: Emergence of a dhfr mutation conferring highlevel drug resistance in Plasmodium falciparum populations from southwest Uganda. J Infect Dis 2008, 197:1598-1604. 
14. Andriantsoanirina V, Ratsimbasoa A, Bouchier C, Jahevitra M, Rabearimanana S, Radrianjafy R, Andrianaranjaka V, Randriantsoa T, Rason MA, Tichit M, Rabarijaona LP, Mercereau-Puijalon O, Durand R, Ménard D: Plasmodium falciparum drug resistance in Madagascar: facing the spread of unusual pfdhfr and pfmdr-1 haplotypes and the decrease of dihydroartemisinin susceptibility. Antimicrob Agents Chemother 2009, 53:4588-4597.

15. Maiga O, Djimde AA, Hubert V, Renard E, Aubouy A, Kironde F, Nsimba B, Koram K, Doumbo OK, Le Bras J, Clain J: A shared Asian origin of the triple-mutant dhfr allele in Plasmodium falciparum from sites across Africa. J Infect Dis 2007, 196:165-172.

16. Menard D, Andriantsoanirina V, Jahevitra M, Barnadas C, Tichit M, Bouchier C, Hopkins Sibley C: Dihydrofolate reductase $1164 \mathrm{~L}$ mutation in Plasmodium falciparum, Madagascar. Emerg Infect Dis 2008, 14:1166-1167.

17. Lozovsky ER, Chookajorn T, Brown KM, Imwong M, Shaw PJ, Kamchonwongpaisan S, Neafsey DE, Weinreich DM, Hartl DL: Stepwise acquisition of pyrimethamine resistance in the malaria parasite. Proc Natl Acad Sci USA 2009, 106:12025-12030.

18. Menard D, Ratsimbasoa A, Randrianarivelojosia M, Rabarijaona LP, Raharimalala L, Domarle O, Randrianasolo L, Randriamanantena A, Jahevitra M, Andriantsoanirina V, Rason MA, Raherinjafy R, Rakotomalala E, Tuseo $L$, Raveloson A: Assessment of the efficacy of antimalarial drugs recommended by the National Malaria Control Programme in Madagascar: up-dated baseline data from randomized and multi-site clinical trials. Malar J 2008, 7:55.

19. Rakotonirina H, Barnadas C, Raherijafy R, Andrianantenaina H, Ratsimbasoa A, Randrianasolo L, Jahevitra M, Andriantsoanirina V, Menard D: Accuracy and reliability of malaria diagnostic techniques for guiding febrile outpatient treatment in malaria-endemic countries. Am J Trop Med Hyg 2008, 78:217-221.

20. de Monbrison F, Angei C, Staal A, Kaiser K, Picot S: Simultaneous identification of the four human Plasmodium species and quantification of Plasmodium DNA load in human blood by real-time polymerase chain reaction. Trans R Soc Trop Med Hyg 2003, 97:387-390.

21. Andriantsoanirina V, Bouchier C, Tichit M, Jahevitra M, Rabearimanana $S$, Randrianjafy R, Ratsimbasoa A, Mercereau-Puijalon O, Durand R, Menard D: Origins of the recent emergence of Plasmodium falciparum pyrimethamine resistance alleles in Madagascar. Antimicrob Agents Chemother 54:2323-2329.

22. Desjardins RE, Canfield CJ, Haynes JD, Chulay JD: Quantitative assessment of antimalarial activity in vitro by a semiautomated microdilution technique. Antimicrob Agents Chemother 1979, 16:710-718.

23. Hastings MD, Bates SJ, Blackstone EA, Monks SM, Mutabingwa TK Sibley CH: Highly pyrimethamine-resistant alleles of dihydrofolate reductase in isolates of Plasmodium falciparum from Tanzania. Trans $R$ Soc Trop Med Hyg 2002, 96:674-676.

24. Basco LK, Ramiliarisoa O, Le Bras J: In vitro activity of pyrimethamine, cycloguanil, and other antimalarial drugs against African isolates and clones of Plasmodium falciparum. Am J Trop Med Hyg 1994, 50:193-199.

doi:10.1186/1475-2875-10-283

Cite this article as: Andriantsoanirina et al: In vitro susceptibility to pyrimethamine of DHFR I164L single mutant Plasmodium falciparum. Malaria Journal 2011 10:283.

\section{Submit your next manuscript to BioMed Central and take full advantage of:}

- Convenient online submission

- Thorough peer review

- No space constraints or color figure charges

- Immediate publication on acceptance

- Inclusion in PubMed, CAS, Scopus and Google Scholar

- Research which is freely available for redistribution 